\title{
Forum
}

\section{Weather Routing and Climatic Routes Across the North Atlantic}

\author{
Adam Wolski \\ (Polish Steamship Company, Szczecin)
}

I. INTRODUCtIon. Shipping routes across the North Atlantic are either climatic, established on the basis of charts showing mean wind and current velocities, the currents of fog, ice limits and the frequency of gales, or are recommended by weather routing agencies on the basis of medium and long-term weather forecasts and the performance of the ship in question.

In the United States and Western Europe weather routing in this sense began in 1954 and in the Soviet Union in 1964. The first Polish shipowner to apply optimum weather routes was the Polish Steamship Company of Szczecin which, in 1974, started issuing its ships with weather route advice.

This note evaluates from the author's own researches the hydro-meteorological conditions experienced on the North Atlantic during 52 voyages by 32000 d.w.t. cargo vessels belonging to the Polish Steamship Company.

2. METHOD. On departure, the ship here called the real ship received from the routing office the information which determined the recommended route between the port of departure and port of destination. At the same time it was assumed that a theoretical ship left the same port for the same destination following a climatic route determined from navigational publications such as Routing Charts, Ocean Passages for the World, pilot charts, Monatkarten, etc. Her movements and responses to waves were determined on the basis of performance curves and facsimile charts of wind and wave analyses.

On reaching the destination or an oceanic terminal point the hydro-meteorological information for both ships on the voyage was collated, including heading angle and wind speed for every $30^{\circ}$ and heading angle and wave height for every $30^{\circ}$.

For the analysis two basic factors affecting the ship's speed, namely wind force and wave force in relation to heading angle, were considered. The performance curve for the ships in question indicated that the greatest loss of speed had occurred when the heading angle was $0-60^{\circ}$, the wave height in excess of $5 \mathrm{~m}$ and the ship's speed about $25 \mathrm{kt}$.

From these findings two patterns have been constructed (Table 1 ), divided into four fields numbered I to 4 , showing the periods of time during which the ships remained in the defined hydro-meteorological conditions. The number of days in each field was then compared for wave and wind for both weather and climatic routes to find out whether the difference in meteorological conditions on both routes was significant. A test was used for two symptoms of structure. The hypotheses were considered on the significance level $\alpha=0.05$. 
TABLE I. TIME SPENT IN DEFINED HYDRO-METEOROLOGICAL CONDITIONS

\begin{tabular}{ccccc}
\hline Heading angle & \multicolumn{2}{c}{ Wave height $(\mathrm{m})$} & \multicolumn{2}{c}{ Wind speed $(\mathrm{kt})$} \\
\hline $0-60^{\circ}$ & $0-4.9$ & $5-12$ & $0-24.9$ & $25-65$ \\
$90-180^{\circ}$ & 1 & 2 & 1 & 2 \\
\hline
\end{tabular}

TABLE 2. TIME COMPARISON OF PERIOD IN DEFINED WIND AND WAVE CONDITIONS

\begin{tabular}{|c|c|c|c|}
\hline $\begin{array}{l}\text { Elements } \\
\text { examined }\end{array}$ & $\begin{array}{c}\text { Europe- } \\
\text { Gulf of Mexico }\end{array}$ & $\begin{array}{c}\text { Gulf of Mexico- } \\
\text { Europe }\end{array}$ & $\begin{array}{c}t \\
(\propto=0.05)\end{array}$ \\
\hline \multicolumn{4}{|c|}{ Waves } \\
\hline I & $1 \cdot 676$ & $2 \cdot 143$ & 1.960 \\
\hline 2 & 3.815 & 2.000 & \\
\hline 3 & 2.024 & 0.340 & \\
\hline 4 & 3.252 & 3.053 & \\
\hline \multicolumn{4}{|c|}{ Wind } \\
\hline I & $1 \cdot 800$ & $7 \cdot 410$ & $1 \cdot 960$ \\
\hline 2 & 3.450 & $2 \cdot 500$ & \\
\hline 3 & $2 \cdot 449$ & $2 \cdot 280$ & \\
\hline 4 & 2.599 & $4 \cdot 167$ & \\
\hline
\end{tabular}

Table 3. Comparison of period spent in defined wave and Wind conditions

\begin{tabular}{|c|c|c|c|}
\hline $\begin{array}{l}\text { Elements } \\
\text { examined }\end{array}$ & $\begin{array}{c}\text { Europe-- } \\
\text { USA/Canada }\end{array}$ & $\begin{array}{l}\text { USA/Canada- } \\
\text { Europe }\end{array}$ & $\begin{array}{c}t \\
(\alpha=0.05)\end{array}$ \\
\hline \multicolumn{4}{|c|}{ Waves } \\
\hline I & 0.202 & $2 \cdot 304$ & $1 \cdot 960$ \\
\hline 2 & 2.794 & 2.056 & \\
\hline 3 & 1.719 & 0.123 & \\
\hline 4 & 0.983 & 7.600 & \\
\hline \multicolumn{4}{|c|}{ Wind } \\
\hline I & 0.274 & 2.583 & 1.960 \\
\hline 2 & 2.792 & $2 \cdot 176$ & \\
\hline 3 & $1 \cdot 868$ & $I \cdot 390$ & \\
\hline 4 & $I \cdot I 54$ & 3.063 & \\
\hline
\end{tabular}

A reduction of the time the ship stays in stormy conditions significantly affects safety and lowers the shipowner's loss from damage to the hull or cargo. To prevent excessive resonance due to hull vibrations and to prevent damage from seas breaking on deck the ships analysed were forced to reduce speed at wave heights above $5 \mathrm{~m}$. For this reason hydro-meteorological conditions characterized by waves about $5 \mathrm{~m}$ in height with wind speeds above $25 \mathrm{kt}$ were defined as stormy. A time comparison of the ship's stay in such conditions in fields 2 and 4 is shown in Tables 2 and 3 .

3. HYDRO-METEOROLOGICAL CONDITIONS. During the voyages from Europe to the Gulf of Mexico, the ships on recommended as opposed to climatic routes stayed 
a shorter time on fields 2 and 4 because for waves the time $(t)=3.815>1.96=t_{\alpha}$ and $(t)=3.252>1.96=t_{\alpha} ;$ and for wind $t=3.45>1.96=t_{\alpha}$ and $(t)=2.599>$ $1 \cdot 96=t_{\alpha}$ (Table 2).

During the voyages from the Gulf of Mexico to Europe, the ships on recommended routes also spent less time in fields 2 and 4 (stormy conditions) because for waves $(t)=2.00>1.96=t_{\alpha}$ and $(t)=3.053>1.96=t_{\alpha} ;$ and for wind $(t)=2.50>$ $1 \cdot 96=t_{\alpha}$ and $(t)=4 \cdot 167>1 \cdot 96=t_{\alpha}$ (Table 2).

More favourable conditions were also encountered by the ships on the recommended routes from Europe to the ports of USA and Canada and back (Table 3 ).

4. CONCLUSION. The hydro-meteorological conditions encountered point to the superiority of recommended routes over climatic ones. Taking advantage of the routes recommended by routing agencies, the ships sailing from Europe to North America reduced the number of days spent in the stormy area from 2 I per cent to 3.9 per cent of the voyage for waves and 29.2 per cent to ro per cent of the voyage for wind.

On the way back from North America to Europe the efficiency of the recommended routes was also considerable. The length of time spent in areas of wave height above $5 \mathrm{~m}$ was lowered from 20.5 per cent to 5 per cent and for wind from 39.5 per cent to 27.1 per cent of the whole voyage as compared with the climatic routes.

\title{
A World-wide Mechanization in Inertial Navigation Systems
}

\author{
G. Del Core and V. Nastro \\ (Istituto Universitario Navale, Naples)
}

An algorithm for inertial navigation by means of which the motion of the vehicle is referred to a developable surface tangential to the Earth is derived.

A first advantage is that the proposed scheme has no singularities at the pole. The algorithm is thus simpler than wander azimuth mechanization because the wander angle is a simple function of the longitude and the solution of six or more direction cosine differential equations is not necessary.

A further advantage is that the method allows the representation of the motion of the vehicle directly on a nautical chart.

It is well known that in inertial systems with gimballed platforms, the outputs of the horizontal accelerometers are employed to derive the ground velocity components of the vehicle in platform coordinates.

If the platform is locally level and north-pointing, east and north velocities $\left(V_{e}, V_{n}\right)$ are directly derived and easily converted into latitude-longitude coordinates $(\phi, \lambda)$ through dead-reckoning equations. Yet in high latitudes such a mechanization becomes difficult because of the convergence of the meridians; the azimuth rotation of the platform is a tangent function of latitude, and consequently as latitude increases such rotation approaches infinity.

This inconvenience is removed by varying the azimuth precession rate (wander 